Military Technical College

Kobry El-Kobbah, Cairo, Egypt.

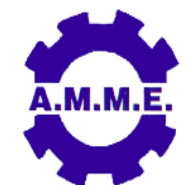

$18^{\text {th }}$ International Conference on Applied Mechanics and Mechanical Engineering.

\title{
DEVELOPMENT AND SOUND ABSORPTION TESTING OF A POROELASTIC KENAF/SISAL FIBRE COMPOSITE TRIM FOR LOWERING OF VEHICLE CABIN NOISE LEVELS
}

\author{
R. K. Dunne ${ }^{1}$, D. A. Desai ${ }^{2}$ and R. Sadiku ${ }^{3}$
}

\begin{abstract}
The automotive industry is under pressure to produce a product (vehicle) that is more recyclable and environmentally-friendly with a high fuel efficiency. At the same time, customers are looking for a vehicle that will provide them with a comfortable ride and low cabin noise levels. Therefore, the present work is concerned with the development and characterization of new poroelastic natural fibre-based sound absorbers, which have not yet been contemplated. This newly developed material is to be recyclable and in addition, be an environmentally-friendly alternative to synthetic absorbers which are currently used as internal trims in vehicles. Therefore, several sound absorber variants, based on the above, were developed and tested in order to select an optimally performing product. These sound absorbers are made of different ratios of kenaf and sisal fibres, which are held together by Acrylonitrile Butadiene Styrene (ABS) matrix. On evaluation of the results, it was found that the proposed sound absorbers have airflow resistivity and sound absorption coefficient values compatible to that of normal practice.
\end{abstract}

\section{KEYWORDS}

kenaf-sisal ABS composite, automotive, airflow resistivity, environment.

1 Junior Lecturer, Dept. of Mechanical Engineering, Mechatronics and Industrial Design, Tshwane University of Technology, South Africa.

2 Section Head, Senior Lecturer, Dept. of Mechanical Engineering, Mechatronics and Industrial Design, Tshwane University of Technology, South Africa.

3 Professor, Dept. of Chemical, Metallurgical and Material Engineering, Tshwane University of Technology, South Africa. 


\section{INTRODUCTION}

The need for light weight environmentally-friendly products, especially in the automotive industry, is increasing every year. This is due to an attempt made to move away from petroleum-based products (e.g. synthetic fibres). The growing concern and increased awareness of the environment is one of the key factors that have influenced this move [1].

Taylor et al [2], reported that the transport sector contributes about $25 \%$ of worldwide $\mathrm{CO}_{2}$ emissions, where cars and trucks account for the bulk of these emissions (about $75 \%$ worldwide). The large amount of $\mathrm{CO}_{2}$ emissions produced by the automotive industry each year has caused governing bodies to release reports in order to help in the formulation of strategies to reduce $\mathrm{CO}_{2}$ emissions. Such strategies include, Reducing Greenhouse Gas Emissions from U.S. Transportation [3] and Canada's Road Transportation Emissions Reduction Strategies [4].

The stringent requirements for the automotive industry, set in reports such as [3, 4], are pushing the automotive industry to produce products that are lighter, more recyclable, have higher fuel efficiency and are more environmentally-friendly. These requirements push the automotive industry to consider alternative materials in the development of interior trim components, such as: headliners, seat backs, side and back door panels and boot liners. The interior trim components have multifunctionality since weight is a major factor. Hence, the internal trims should be aesthetically appealing, have good sound absorbing properties (in order to reduce cabin sound pressure levels), should have sufficient strength for the required application and be easily recyclable.

Therefore, this paper focused on the manufacturing and airflow resistivity testing of an environmentally-friendly poroelastic natural fibre composite sound absorber, for the purpose of reducing internal vehicle cabin noise levels.

\section{DETERMINATION OF AIRFLOW RESISTIVITY}

One of the methods used to determine a porous materials ability to absorb sound energy and hence reduce noise within an enclosed volume, is its airflow resistivity. The method used in this study, to determine the airflow resistivity, was based on the steady-state method of the ISO 9053 standard. Great care was taken in following the standard.

In the steady-state method, air with a definite velocity and volumetric flow rate, which is prescribed by the ISO 9053 standard, flows through a tube (cell) with diameter $\geq 95 \mathrm{~mm}$. The volumetric airflow in the cell and flowing through the porous material should be laminar, in order to reduce viscous losses. The porous material is placed at a defined distance in the cell and is held in place by a piston, while the laminar air flows through the porous specimen as seen in Fig. 1.

When calculating the resistance that a porous material offers against airflow, it is important to properly define what is meant. Since there are three so-called different ways of defining the airflow resistance of a porous material; all of which are defined by ISO 9053 [5]. The first one defines the airflow resistance $R$, as: 


$$
R=\frac{\Delta p}{q_{v}}
$$

where $\Delta p$ is the air pressure difference across the porous material specimen with respect to atmosphere in $[\mathrm{Pa}]$, and $q_{v}$ is the volumetric airflow rate passing through the porous specimen in $\left[\mathrm{m}^{3} / \mathrm{s}\right]$.

The second definition is the specific airflow resistance, $R_{S}$, which is represented by Eqn. (2). In acoustics, this quantity is more frequently used and according to Milan et al [6], this might be because it represents the acoustic impedance of the material. The specific airflow resistance is:

$$
R_{S}=R A
$$

where $A$ is the cross-sectional area of the test specimen perpendicular to the direction of airflow in $\left[\mathrm{m}^{2}\right]$.

The third definition is the airflow resistivity, which is defined by Eqn. (3). The airflow resistivity, $r$, is the quantity that is of most importance in this study. Since, its value is used in the selection of the absorber thickness. In the automotive industry, this is of great importance due to stringent space and weight constraints. Airflow resistivity is represented by:

$$
r=\frac{R_{S}}{d}
$$

where $r$ is the thickness of the absorber in the direction of airflow in [m].

\section{MANUFACTURING AND AIRFLOW RESISTIVITY TESTING OF POROUS MATERIAL}

Before the manufacturing of a sound absorbing material begins, it is necessary to consider the end application and its desired performance. In the development of a sound absorber for the automotive industry, it is not always possible to facilitate all the stringent requirements necessary, e.g. low weight, high fire resistance, high sound absorption, easy mould ability, low volume etc. Since it is often the case, that these properties are dependent on each other for example, high sound absorption in the low frequency range requires a thicker porous material (greater volume needed) and high sound absorption in the high frequency range requires a denser porous material (greater weight). Therefore, it is a challenging task to overcome these requirements and hence, careful planning is of essence.

The main objective of the present work is to create a natural fibre sound absorber that can compete with synthetic based sound absorbers in terms of sound absorption or attenuation. Furthermore, regarding the main properties mentioned above, the sound absorption ability of the developed porous absorbers is the only parameter of concern and hence will be investigated, since the sound absorption is the objective function in this study. 


\section{Manufacturing of Porous Absorber}

In the present work, the natural fibres (kenaf and sisal) employed to fabricate the porous absorbers were used without any additional surface treatments, such as chemical or physical treatments. Jayaramudu et al [7], stated that these treatments are often used to alter the mechanical, morphological and chemical resistance characteristics of the natural fibres and reduce fibre pull-out. Therefore, the natural fibres (kenaf and sisal) for the present investigation were used in their raw natural states.

\section{Fibre Preparation}

During the preparation of the natural fibre composites, the natural fibres were weighed using a highly accurate calibrated digital scale Model (OHAUS Pioneer), with an accuracy of \pm 0.1 milligrams. In order to fabricate a low density composite the mass of natural fibre used was $64.125 \mathrm{~g}$ for each composite. The natural fibres were then cut to an average length of $10 \mathrm{~mm}$. However, due to the tortuousness of the sisal and kenaf fibres, the fibre length ranged between $15-82 \mathrm{~mm}$. These natural fibres were selected due to their low cost, good sound absorption performance, biodegradability and recyclability, as reported by Dunne et al. [1], Asdrubali [8] and Azevedoa and Nabuco [9]. Some of the fibre properties are listed in Table 1.

\section{Fibre Shaping Mould}

The mould used to shape the natural fibre composites, into a rectangular shape, was made of mild steel. The mould cavity had dimensions of $285 \times 300 \times 10 \mathrm{~mm}$. A mild steel lid was fabricated in order to compress the natural fibre composites into a uniform thickness. The mould and lid is depicted in Fig. 2.

\section{Composite Fabrication Process}

The cut natural fibres were subsequently hand-laid in the mould and evenly distributed. The lid was then placed on top of the fibres and clamped down, as shown in Fig. 2. The matrix solution used to bind the fibres was prepared using ABS, which was mixed with acetone.

ABS is a common thermoplastic and it is widely used in industry due to its excellent mechanical properties, recyclability, chemical resistance and ease of processing, as reported by Ahmad et al [10]. The polymer ABS was dissolved in acetone, thus making it fluidic and allowing it to flow through the composite and around the fibres. ABS used in this study was obtained from 3D printing scrap and is known as Z-ABS. The recycling of the $3 \mathrm{D}$ printing scrap for the matrix, adds to the environmentalfriendliness of the proposed composites, since the 3D scrap would have been discarded.

A ratio of 10:1 was used to make the solution, i.e. 10 parts of acetone to every 1 part of $A B S$. This ratio was chosen in order to allow the ABS solution to easily flow through the composite without building up. The ABS was left to fully dissolve in the acetone before being used. When the ABS was fully dissolved, the natural fibre composite was removed from the mould and placed on a metal wire mesh for easy handling. The fibre composites were then dipped into the solution and the solution 
was poured over the composite in order to make sure that all the fibres were coated, as shown in Fig. 3.

The ABS-natural fibre composites were then left to dry. Once the composites were dried, the process was repeated to ensure sufficient fibre-matrix bonding. The composites were then left for 24 hours, to fully dry. Thereafter, circular specimens, as prescribed by ISO 9053 standard, were cut to a diameter of $98 \mathrm{~mm}$, for the purpose of airflow resistivity testing, as depicted in Fig. 4. The letter and number written on the specimens represent the percentage of fibre per total mass of fibre used, for example: S30 denotes a sample containing $30 \%$ of sisal fibre and $70 \%$ kenaf fibre.

\section{Equipment Used for Airflow Resistivity Testing}

The equipment used for the testing of airflow resistivity was chosen based on the ISO standard 9053 . Every attempt was made to follow, rigorously the ISO 9053 standard, in terms of the test equipment and the manufacturing of the test cell. Hence, a Dwyer Rate-Master flowmeter, with an accuracy of $\pm 3 \%$, was used to measure the volumetric flow rate of the air. A differential pressure-measurement device model A2G-50 with a measuring accuracy of $\pm 1.5 \%$, was used to measure the pressure difference across the porous specimen. Furthermore, the test cell was manufactured from a mild steel tube of circular cross-section, with an inside diameter of $98 \mathrm{~mm}$. The test cell inlet section was $300 \mathrm{~mm}$ in length, thus allowing laminar flow to take place. The tapping point, for the measuring of pressure, was placed at a distance of $30 \mathrm{~mm}$ from the specimen on the inlet side of the cell. A piston with a thickness indicator was used to hold the specimen in place, during testing, and this allows for an accurate reading of the specimen's thickness.

\section{Test Procedure}

1. Equipment was setup and checked for any air leakages or faults, as shown in Fig. 5.

2. Each test specimen was numbered, for precise data collection, and then placed in the test cell.

3. In order to ensure that no air leakages occurred around the edges of the specimen, petroleum jelly was used to seal the edges as recommended by ISO 9053 standard.

4. The piston was then pushed in, to hold the specimen in place and the thickness of the specimen was read off the thickness indicator. The thickness of the porous test specimens were also measured using a Vernier Calliper for better accuracy.

5. The adjustable airflow control valve was then opened up and set to the required volume flow rate. Since the airflow resistance increases with increased volume flow rate due to viscous effects, it was necessary to work with low flow rates as prescribed by the standard. Therefore, the applied flow rates were between $1 \mathrm{~L} / \mathrm{min}$ to $9.5 \mathrm{~L} / \mathrm{min}$ were used.

6. The change in pressure at the prescribed volume flow rate was then captured by the differential pressure transducer and manually recorded.

7. The volume flow rate was then increased and the procedure, as described in point 6 above, was repeated. This was performed a number of times in order to improve the accuracy of the measured parameters which, in turn, were used to calculated the airflow resistivity. This was implemented since more readings of 
the pressure difference at different volume flow rates decreases the inaccuracies associated with human and test equipment errors.

\section{RESULTS AND DISCUSSION}

Once the data was acquired, the airflow resistivity was calculated by using Eqn. (3) and listed according to specimen thickness and flow rate as depicted in Table 2. It can be seen from Table 2, that the airflow resistance, calculated using Eqn. (1), increases with increasing thickness and percentage of Sisal fibre in the composite. According to Schiavi et al. [11], this is expected since airflow resistance varies linearly with material thickness at constant density. However, the airflow resistivity, of a composite, should be constant at constant density, which is the case for the majority of the composites under investigation as seen in Table 2 . This is reiterated by Berardi et al. [12], who states that the thickness of the composite should not have an effect on the airflow resistivity. Also, the airflow resistance verse thickness can be seen, graphically in Fig. 6.

From Table 2, it can be observed that the $30 \%$ sisal composite, has an average airflow resistivity of $2336 \mathrm{~Pa} / \mathrm{m}^{2}$ at the low end and the $60 \%$ sisal has an average airflow resistivity of $3689 \mathrm{~Pa} / \mathrm{m}^{2}$ at the high end. It should be noted that the variation in airflow resistivity observed in Table 2 , is most likely due to inaccuracies that occur during testing and viscous affects caused from the changes in volumetric flow rate during testing, hence the reason for using an averaged airflow resistivity value. These values are comparable with normal practice, since materials, such as: cotton shoddy, sisal, hemp, kenaf, cotton linen and coconut fibre have airflow resistivity values ranging from $320 \mathrm{~Pa} / \mathrm{m}^{2}$ for cotton shoddy, with a density of $42.892 \mathrm{~kg} / \mathrm{m}^{3}$, at the low end to $2700 \mathrm{~Pa} / \mathrm{m}^{2}$ for kenaf at a density of $47 \mathrm{~kg} / \mathrm{m}^{3}$ at the high end [13],[14],[15],[16],[17, 18]. Out of the three fibre composites presented, the $60 \%$ sisal ABS composite performed the best. The reason the $40 \%$ sisal composite had the lowest airflow resistivity may be due to the fact that it had the lowest density, hence less fibres per volume, which is expected to affect the viscous losses.

The Delany-Bazley empirical model as seen in Eqn. (4), was used to predict the sound absorption coefficient, since it is the most accurate model with regard to natural fibres [19]. The sound absorption coefficient, for each composite, was plotted using a developed Python script; this is depicted in Fig. 7. It can be seen from Fig. 7 that the $60 \%$ sisal fibre composite has the highest sound absorption coefficient over the whole frequency range. However, it should be noted that the graphs in Fig. 7, where predicted using an average airflow resistivity, since the airflow resistivity of a porous material is a constant and should only vary slightly with an increase in volume flow of air through the porous medium due to increasing viscous affects.

$$
Z_{C}=\rho_{0} c_{0}\left[1+0.0571\left(\frac{\rho_{0} f}{\sigma}\right)^{-0.754}-i 0.087\left(\frac{\rho_{0} f}{\sigma}\right)^{-0.732}\right]
$$

where $Z_{C}$ is the characteristic impedance, $c_{0}$ is the speed of sound through the porous media, $\rho_{0}$ is the density of air, $f$ is the frequency and $\sigma$ is the airflow resistivity of the porous material. 


\section{CONCLUSION}

This paper presents three new natural fibre sound absorbers, made form a mixture of sisal and kenaf fibres with recycled 3D printing ABS scrap as the matrix. These proposed composites could serve as alternative environmentally-friendly recyclable products to synthetic based products, used in the automotive industry. These materials have shown to have comparable airflow resistivity values when compared to commonly used materials in automotives. It is also shown that the sound absorption coefficient of the developed porous composites is relatively high over the whole frequency range. Although these materials have comparable airflow resistivity values, their densities are relatively high and may need further investigation. On the other hand, these materials may be compressed for panelling usage within the vehicle cabin. It should also be noted that this research is part of an on-going larger project which is focused on the influence various natural fibre composites have on interior vehicle cabin noise levels.

\section{REFERENCES}

[1] R. Dunne, D. Desai, R. Sadiku, and J. Jayaramudu. "A Review of Natural Fibres, their Sustainability and Automotive Applications", J. of Reinforced Plastics and Composites, Vol. 35, No. 13, pp. 1041-50 (2016).

[2] P. Taylor, L. Fulton, and P. Canzzola. "Transport, Energy and $\mathrm{Co}_{2 "}$. In: Wright $R$, editor.: International Energy Agency, (2009).

[3] D.L. Greene, H.H. Baker, and S.E. Plotkin. "Reducing Greenhouse Gas Emissions from U.S. Transportation". Arlington: Center for Climate and Energy Solutions, (2011).

[4] European Commission. "Strategy for Reducing Heavy-Duty Vehicles' Fuel Consumption and CO2 Emissions" Brussels: European Parliament, (2014).

[5] ISO 9053. "Acoustics - Materials for Acoustic Application - Determination of Airflow Resistance", (1991).

[6] K. Milan, R. Branko, G. Vladan, and P. Zvonko. "One Realization of the System for Measuring Airflow Resistance", J. FACTA UNIVERSITATIS, Vol. 12, No. 1, pp. 83-94 (2015).

[7] J. Jayaramudu, G.S.M. Reddy, K. Varaprasad, E.R. Sadiku, S.S. Ray, and A.V. Rajulu, A.V. "Mechanical Properties of Uniaxial Natural Fabric Grewia tilifolia Reinforced Epoxy Based Composites: Effects of Chemical Treatment", J. Fibers and Polymers, Vol. 15, No. 7, pp. 1462-8 (2013).

[8] F. Asdrubali. "Survey on the Acoustical Properties of New Sustainable Materials for Noise Control", Euronoise, Tampere, Finland, (2006).

[9] L. Azevedoa, and M. Nabuco. "Sound Absorption of Sisal Fiber Panels", The 2005 Congress and Exposition on Noise Control Engineering. Rio de Janeiro, Brazil, Institute of Noise Control Engineering ( INCE ), (2005).

[10] F. Ahmad, F. Bateni, M.S. Tavana, and A.S. Yahaya. "Application of Thermoplastics in Protection of Natural Fibres, Thermoplastic Elastomers", In: El-Sonbati PA, InTech, (2012).

[11] A. Schiavi, C. Guglielmone, P. Miglietta, and F. Alasia. "Influence of StaticLoad on Airflow Resistivity Determination", Acoustics 08, Paris, (2008).

[12] U. Berardi, and G. lannace. "Predicting the Sound Absorption of Natural Materials: Best-Fit Inverse Laws for the Acoustic Impedance and the Propagation Constant", J. Applied Acoustics, Vol, No. 115, pp. 131-8 (2017). 
[13] W. Fung, and M. Hardcastle. "Textiles in automotive engineering", Cambridge: Woodhead Publishing Limited, (2001).

[14] F.A. Everest, and K.C. Pohlmann. "Absorption". Master Handbook of Acoustics. $5^{\text {th }}$ ed: McGraw-Hill, (2009).

[15] U. Berardi, and G. lannace. "Acoustic Characterization of Natural Fibers for Sound Absorption Applications", J. Building and Environment, Vol. 94, pp. 84052 (2015).

[16] J. Ramis, J. Alba, R. del Rey, et al. "New Absorbent Material Acoustic Based on Kenaf's Fibre", J. Materiales de Construcción, Vol. 60, No. 299, pp. 133-43 (2010).

[17] J. Cherng. "Smart Acoustic Material for Automotive Applications", Dearborn: The University of Michigan-Dearborn, (2005).

[18] A. Grefrath. "Application of Natural Fibres in Vehicle Interiors", J. LANDTECHNIK, Vol. 2001, pp. 228-9.

[19] R. Dunne, A. Desai and R. Sudiku. "A Review of the Factors that Influence Sound Absorption and the Available Empirical Models for Fibrous Materials", J. Acoustics Australia, Vol. 45, pp. 453-69 (2017).

\section{FIGURES AND TABLES}

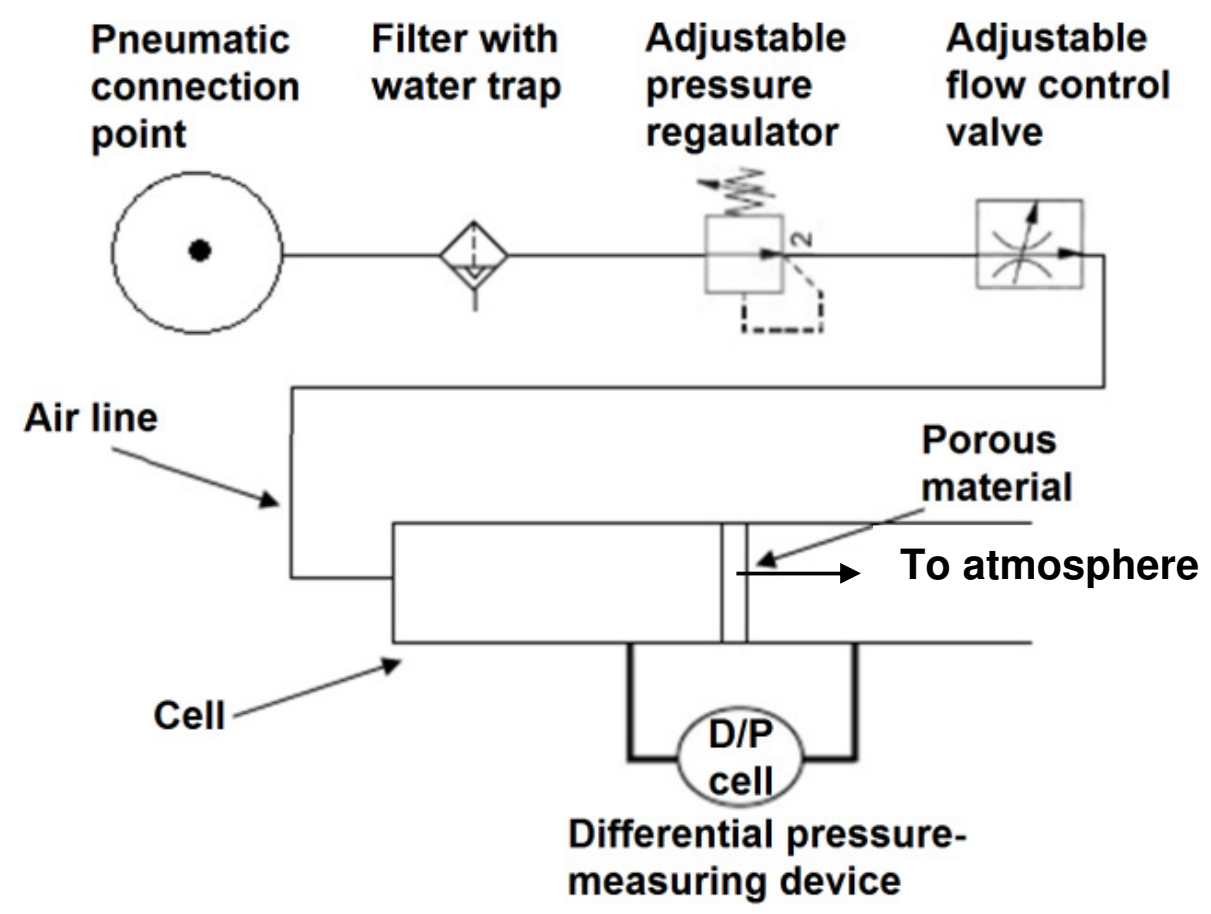

Fig.1. Schematic setup of airflow resistivity test. 


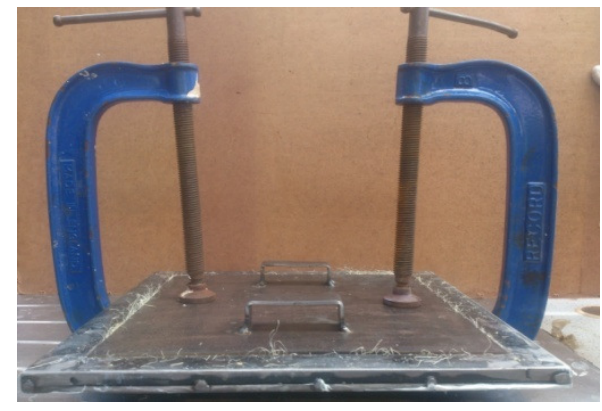

Fig.2. Compressing fibres in mould.

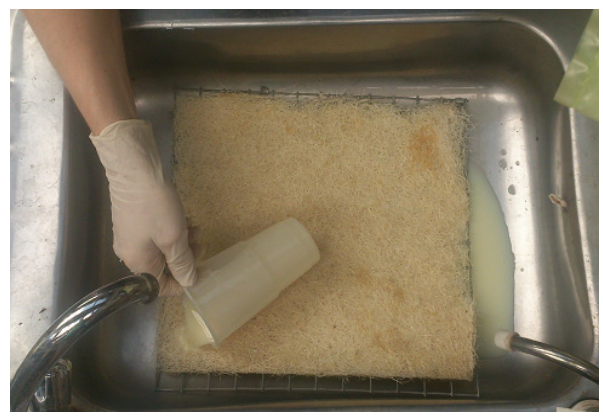

Fig.3. Coating natural fibres with ABS.

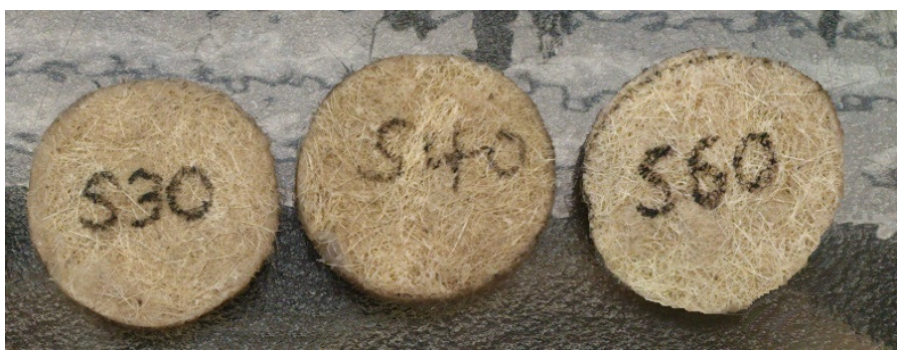

Fig.4. Kenaf/sisal natural fibre circular specimens.

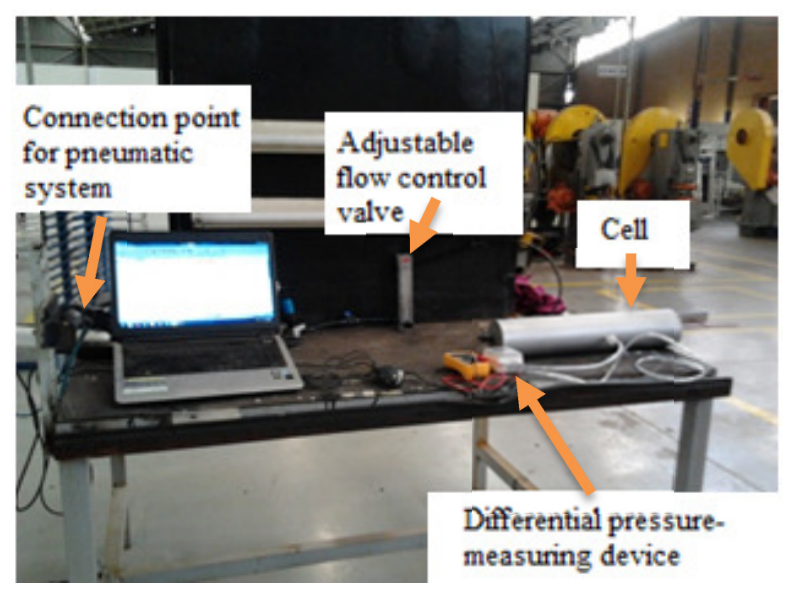

Fig.5. Airflow resistivity test setup. 


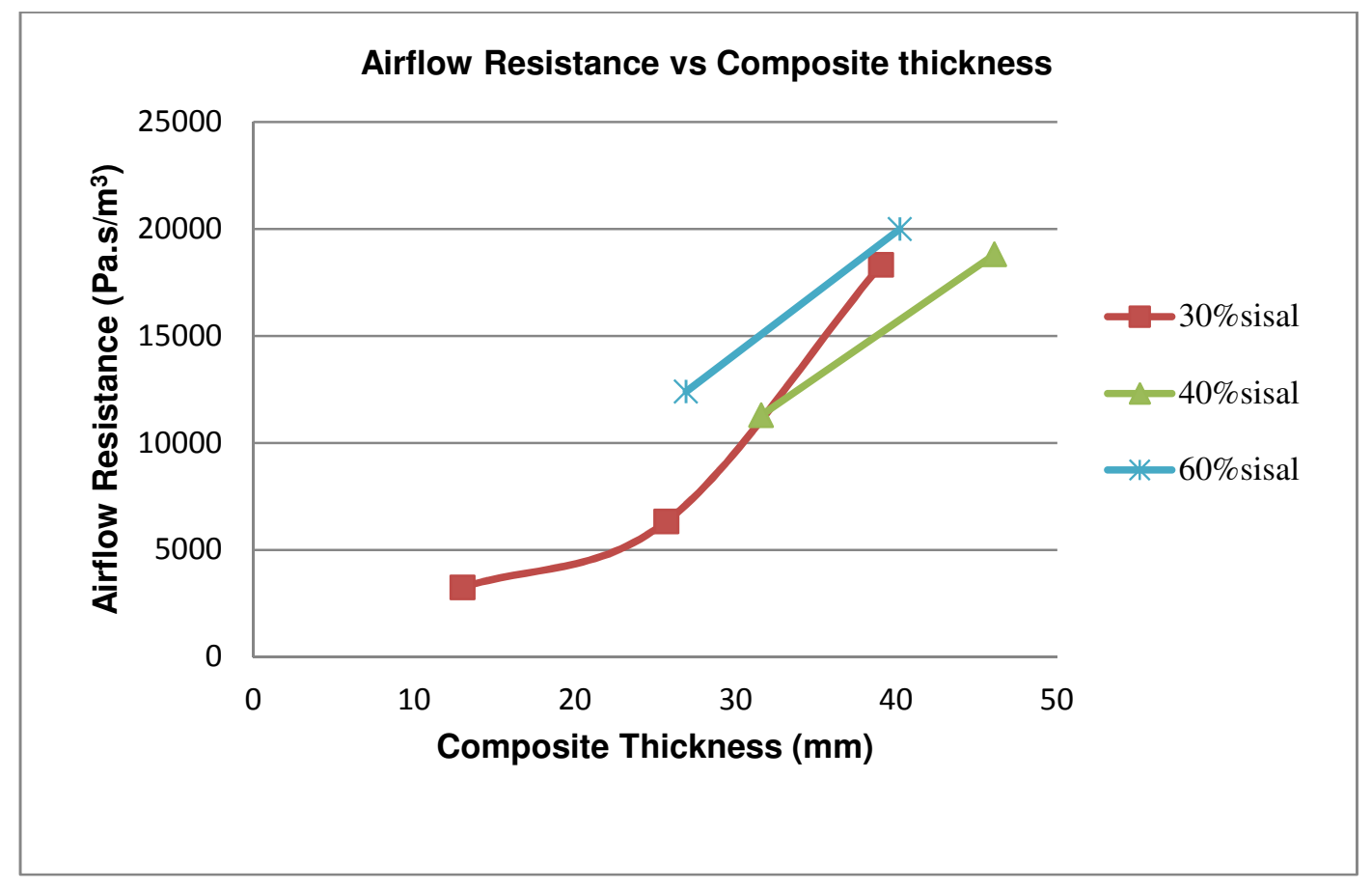

Fig.6. Airflow resistance verse composite thickness.

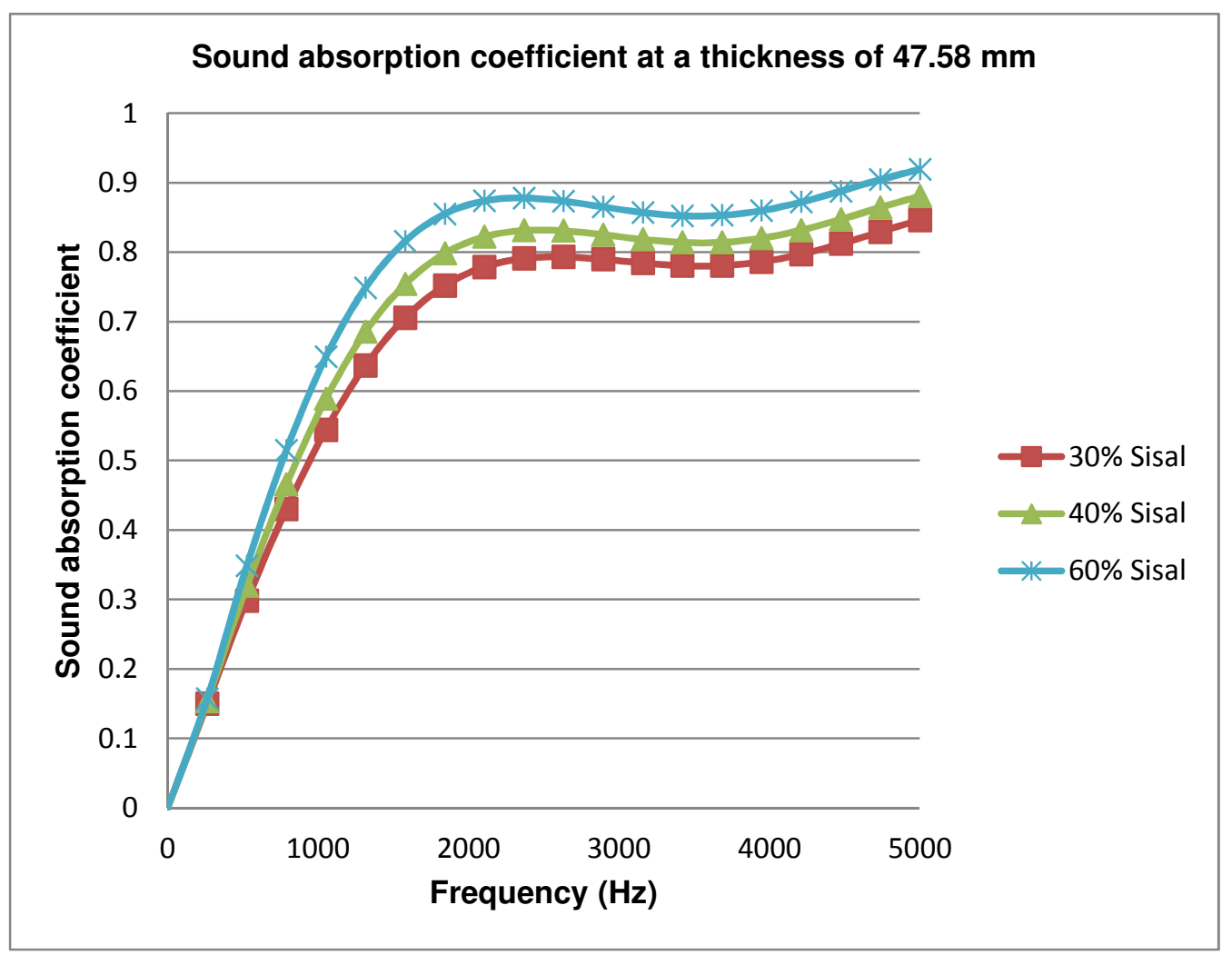

Fig.7. Sound absorption coefficient. 
Table 1. Acquired fibre physical properties.

\begin{tabular}{|c|c|c|}
\hline Fibre Properties & Kenaf fibre & Sisal fibre \\
\hline Fibre density $\left(\mathrm{kg} / \mathrm{m}^{3}\right)$ & 1250.0 & 1500.0 \\
\hline Fibre diameter $(\mu \mathrm{m})$ & 79.0 & 128.0 \\
\hline
\end{tabular}

Table 2. Measured airflow resistivity of kenaf-sisal/ABS composite

\begin{tabular}{|c|c|c|c|}
\hline Fibre type & $\begin{array}{c}\text { Thickness 1 } \\
(\mathbf{m m})\end{array}$ & $\begin{array}{c}\text { Thickness 2 } \\
(\mathbf{m m})\end{array}$ & $\begin{array}{c}\text { Thickness 3 } \\
(\mathbf{m m})\end{array}$ \\
\hline $30 \%$ sisal & 13.012 & 25.677 & 39.04 \\
\hline Airflow resistivity $\left(\mathrm{Pa} . \mathrm{s} / \mathrm{m}^{2}\right)$ & 1913.248 & 1781.412 & 3313.608 \\
\hline Airflow resistance $\left(\mathrm{Pa} . \mathrm{s} / \mathrm{m}^{3}\right)$ & 3245.614 & 6319.444 & 18319.818 \\
\hline Bulk density $\left(\mathrm{kg} / \mathrm{m}^{3}\right)$ & 106.04 & 106.04 & 106.04 \\
\hline $40 \%$ sisal & - & 31.581 & 46.102 \\
\hline Airflow resistivity $\left(\mathrm{Pa} . \mathrm{s} / \mathrm{m}^{2}\right)$ & - & 2696.366 & 3000.516 \\
\hline Airflow resistance $\left(\mathrm{Pa} . \mathrm{s} / \mathrm{m}^{3}\right)$ & - & 11275.252 & 18801.143 \\
\hline Bulk density $\left(\mathrm{kg} / \mathrm{m}^{3}\right)$ & 77.868 & 77.868 & 77.868 \\
\hline $60 \%$ sisal & - & 26.92 & 40.22 \\
\hline Airflow resistivity $\left(\mathrm{Pa} . \mathrm{s} / \mathrm{m}^{2}\right)$ & - & 3741.029 & 3636.854 \\
\hline Bulk density $\left(\mathrm{kg} / \mathrm{m}^{3}\right)$ & - & 12392.983 & 19991.597 \\
\hline
\end{tabular}

